\title{
Pulsed flow-through cultivation of Margaritifera margaritifera: Effects of water source and food quantity on the survival and growth of juveniles
}

\author{
Heini S. H. Hyvärinen (iD) M. Motiur R. Chowdhury • Jouni Taskinen
}

Received: 30 September 2019/Revised: 25 February 2020/Accepted: 6 March 2020/Published online: 19 March 2020 (C) The Author(s) 2020

\begin{abstract}
Conservation of the endangered freshwater pearl mussel (FPM) includes artificially rearing juveniles, but the pulsed flow-through (PFT) method, enabling the continuous renewal of water and food in culture containers, has not been applied to FPM. This study tested the PFT method in culture of FPM juveniles, and the effect of water source (tap vs well water) and food concentration (mixture of commercial phytoplankton products) on the survival and growth of juveniles. Beaker-specific survival rates varied from 0 to $100 \%$ (mean: $34 \%$ ) and from 0 to $58 \%$ (mean: $16 \%$ ) in the 1st (2-week) and 2nd (10-week) experiment, respectively. In the 1st experiment, juveniles attained statistically significantly bigger sizes and more than two times higher survival in well water than they did in tap water. In both experiments, the food concentration of $0.250 \mu \mathrm{l} / \mathrm{l}$ resulted in the highest survival (compared to other concentrations ranging from 0.125 to $0.500 \mu \mathrm{l} / \mathrm{l})$. However, food concentration did not have a significant effect on size of juvenile FPM in either of the experiments. Results indicate that the PFT system
\end{abstract}

Guest editors: Manuel P. M. Lopes-Lima, Nicoletta Riccardi, Maria Urbanska \& Ronaldo G. Sousa / Biology and Conservation of Freshwater Molluscs

H. S. H. Hyvärinen $(\bowtie) \cdot$ M. M. R. Chowdhury ·

J. Taskinen

Department of Biological and Environmental Science,

University of Jyväskylä, P.O. Box 35, 40014 Jyväskylä,

Finland

e-mail: heini.s.h.hyvarinen@jyu.fi is suitable for FPM rearing experiments, but its applicability to mass culture of FPM juveniles requires further investigation.

Keywords Endangered species - Freshwater pearl mussel $\cdot$ Captive breeding - Artificial culture . Unionida

\section{Introduction}

The freshwater pearl mussel, Margaritifera margaritifera (Linnaeus, 1758), is an extremely long-lived, critically endangered bivalve occurring in the running waters of the Holarctic region (Moorkens, 2011; Lopes-Lima et al., 2017; IUCN, 2019). The life cycle of M. margaritifera contains critical phases, such as the glochidium larva attaching to Atlantic salmon or brown trout, and the long juvenile stage in the riverbed gravels. Thus, the species is threatened by many anthropogenic environmental disturbances, including pollution, sedimentation, eutrophication, damming, flow changes, invasive salmonids and loss of salmonid host fish (Bauer, 1988; Young, 1991; Young et al., 2001; Österling et al., 2008; Gum et al., 2011; Taskinen et al., 2011; Moorkens \& Killeen, 2014; Gosselin, 2015; Salonen et al., 2016).

Freshwater mussels act as ecosystem engineers, playing an important role in particle processing, 
nutrient release and sediment mixing. By burrowing in the river substrate, freshwater mussels increase water and oxygen penetration through the sediment, release nutrients from sediments and stabilise river substrates (McCall et al., 1979; Matisoff et al., 1985; McCall et al., 1995; Zimmerman \& de Szalay, 2007; Allen \& Vaughn, 2009). By filtering phytoplankton and suspended fine materials, freshwater mussels transport nutrients from the water to the river bed (Howard \& Cuffey, 2006), decreasing chlorophyll- $a$ content and clearing the water (Welker \& Walz, 1998). Mussel shells offer attachment surfaces for bryophytes, which in turn serve as habitat for diverse invertebrate communities (Bowden et al., 1999). Thus, freshwater mussels provide important ecological services and link multiple trophic levels in river ecosystems (Vaughn \& Hankenkamp, 2001; Vaughn et al., 2008; Vaughn, 2018).

Healthy freshwater mussel beds can comprise $50-90 \%$ of the benthic biomass in streams (Negus, 1966; Layzer et al., 1993; Strayer et al., 1999). Because organisms' contribution to ecological processes is directly proportional to their biomass (Strayer et al., 1999; Vaughn et al., 2004), the decline of $M$. margaritifera populations can have remarkable implications for river ecosystems' functioning. Fulfilling the criteria for an indicator, flagship, keystone and umbrella species, M. margaritifera is an ideal target species for conserving aquatic ecosystem functioning (Geist, 2010).

North America has a long tradition of rearing endangered mussel species in the laboratory (Gatenby et al., 1997; Rogers, 1999; Beck \& Neves, 2003; Beaty \& Neves, 2004; Patterson et al., 2018). Rearing facilities for M. margaritifera have also been established in a few European countries (e.g. Czech Republic, Luxembourg, France, UK, Norway, Ireland and Germany), where mussel juveniles are reared until they reach a size where they can survive in natural habitats, even in poor sediment conditions (Schmidt \& Vandré, 2010; Thomas et al., 2010; Gum et al., 2011). Artificial propagation is a central part of $M$. margaritifera conservation and restoration strategies (Hastie \& Young, 2003; Geist, 2010; Gum et al., 2011; LopesLima et al., 2017). Rearing new-born M. margaritifera juveniles can be done in so-called Hruska boxes (Hruska, 1992), in which some of the water (with food) is renewed from time to time. It can also be done using the so-called 'semi-natural' method, with the continuous flow-through of natural river or lake water. Here, no food is added, but the juveniles feed on the nutrition available in the natural water supply (Hastie \& Young, 2003; Lavictoire et al., 2016). The third method for culturing new-born juvenile $M$. margaritifera is to place them directly in hole plates located in rivers (Buddensiek cages) (Buddensiek, 1995), where they feed on natural food, such as phytoplankton, zooplankton and particulate detritus. As an alternative to static box culture, semi-natural methods, or hole plates, flow-through systems, which enable the continuous renewal of water and food, have been developed to rear juvenile mussels (Patterson et al., 2018, Kunz et al., 2020). The flow-through method was first used in ecotoxicology research to expose juvenile mussels to known concentrations of contaminants (Ingersoll et al., 2007) but was further adopted for the captive breeding of mussels (Barnhart et al., 2015; Kunz et al., 2020). In pulsed flow-through (PFT), every $60-90 \mathrm{~min}$, a pulse of 'flow' is automatically delivered to beakers where juvenile mussels are held to change the water, remove waste and deliver food (for details, see Patterson et al., 2018). This system has proven effective for culturing the freshly detached juveniles of Unionidae mussels, and most importantly, western pearl shell, Margaritifera falcata (Gould, 1850), (Patterson et al., 2018; Kunz et al., 2020). As the advantages of the PFT method include individual beakers that can easily be removed for examination, PFT could provide an efficient tool for replicated experiments when studying the optimal conditions (e.g. food type) for raising juvenile $M$. margaritifera. In addition, PFT could be developed into a powerful technique for the mass culturing of $M$. margaritifera juveniles.

For these reasons, this study investigates the suitability of the PFT method to propagate juvenile M. margaritifera. In addition, in pursuance of the suitability test, it examines the effect of the water source (tap vs well water) and different food concentrations on the survival and growth of juvenile $M$. margaritifera. The hypotheses were as follows: (i) the PFT system is suitable for culturing $M$. margaritifera juveniles, (ii) the use of well water results in better success-in terms of the growth and survival of juveniles - than aged tap water and (iii) moderate food concentration results in a better growth and survival of M. margaritifera juveniles than low or high concentrations. 


\section{Materials and methods}

Glochidia source, infestation of host fish and metamorphosis

Rearing experiments were carried out between July and December of 2016. To obtain juvenile mussels, brown trout, Salmo trutta (Linnaeus, 1758), were infested at the Konnevesi Research Station (University of Jyväskylä) on 31 August, 2015 with M. margaritifera glochidia collected from River Jukuanoja, Iijoki River catchment, northern Finland (for the map, see Salonen \& Taskinen, 2017). Brown trout $(1+$ years of age) originated from the Laukaa fish farm of the Natural Resources Institute Finland. The glochidia of $M$. margaritifera were collected using a non-destructive method by placing 30 gravid mussels into buckets with 31 of river water for $30 \mathrm{~min}$ on the day of infestation so that the mussels could be returned to the river after incubation. The timing of the M. margaritifera glochidia collection was based on previous studies on this population (Salonen \& Taskinen, 2017; Chowdhury et al., 2017) to ensure that the glochidia were fully mature. Salonen et al. (2017) found that $M$. margaritifera of River Jukuanoja were specialised to infest brown trout, whereas Atlantic salmon were a poor host. The glochidial suspension was facilitated with aeration and additional water and kept at a low temperature $\left(4-6^{\circ} \mathrm{C}\right)$ to maintain the glochidia's viability during the $500 \mathrm{~km}$ transportation from the river to the research station. Fish were transported to the research station 2 weeks before exposure and kept in a 1631 flow-through tank. Exposure was performed with $14.3 \times 10^{5}$ glochidia for $1.5 \mathrm{~h}$ at a temperature of $16.8^{\circ} \mathrm{C}$. During the exposure, water volume was reduced to 701 , water flow was halted and aeration was provided. Details about the maintenance of the fish over the winter of 2015-2016 and the numbers of M. margaritifera glochidia in the fish can be found in Chowdhury et al. (2019). A total of 159 brown trout were initially infested in 2015 , but only 14 of them were used for juvenile mussel collection in 2016.

In July 2016, the temperature of the fish maintenance tank was raised from $10-12^{\circ} \mathrm{C}$ to $16^{\circ} \mathrm{C}$ to initiate the metamorphosis of the glochidia. Eight randomly selected trout were then moved to the laboratory of the Department of Biological and Environmental Science, University of Jyväskylä and placed in separate 301 buckets with a flow-through of well water at $18^{\circ} \mathrm{C}$. The juvenile mussels (length of approximately $300 \mu \mathrm{m}$ ) were collected from the bucket water with a sieve (mesh size: $100 \mu \mathrm{m}$ ) for the 1st 3-week experiment. In August 2016, the same procedure was repeated with another six trout to obtain $M$. margaritifera juveniles for the 2nd 10-week experiment (see below).

The use of fish in this study was approved by the Animal Experiment Board of Finland (Regional Administration of Southern Finland, license number ESAVI/10184/04.10.07/2014). Collection of M. margaritifera glochidia from River Jukuanoja was performed with license number POPELY/513/07.01/ 2011 from the North Ostrobothnia Regional Centre for Economic Development, Transport and the Environment (Oulu, Finland).

Pulsed flow-through (PFT) system, feeding and water

The individual PFT systems (Fig. 1) (Patterson et al., 2018; Kunz et al., 2020) in the current study included a 401 container with a water-food suspension (16 1 of water added with different amounts of food, see below) and four $250 \mathrm{ml}$ replicate beakers with juvenile mussels. Every hour, an electric valve delivered a

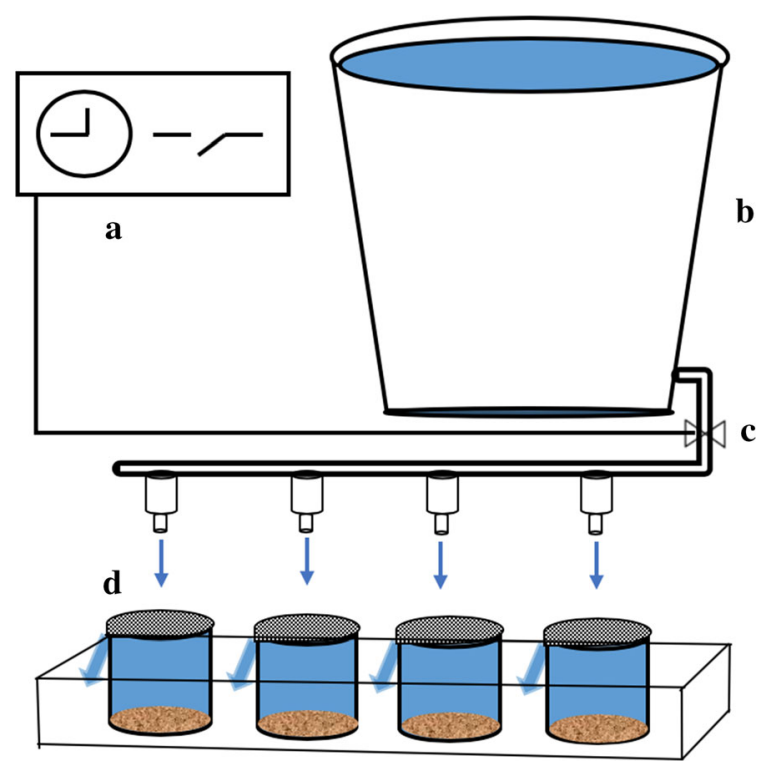

Fig. 1 Schematic drawing of the pulsed flow-through system utilised in this study. The system consists of a a timer, $\mathbf{b}$ a container for water and food solution, $\mathbf{c}$ a timed valve and d delivery manifolds and beakers. The valve connected to the timer automatically delivers the water and food mixture to the beakers through the delivery manifolds 
$125 \mathrm{ml}$ (3 min) pulse of water-food suspension through a splitter to each beaker. Each delivery of water displaced half of the water in the beaker. The juveniles were fed with commercial marine bivalve food Shellfish Diet $1800 \AA$ (dry weight $>8 \%$, cell density circa 2 billion/ml) and Nanno 3600® (dry weight $>18 \%$, cell density circa 68 billion/ml) (Reed Mariculture Inc., USA) in a 1:1 mixture. Every day, the water-food suspension in the container was completely renewed, and the suspension was continuously aerated. Juveniles were contained in the $250 \mathrm{ml}$ beakers with a $1 \mathrm{~mm}$ layer of sand $(125 \mu \mathrm{m}$ in diameter) to provide a substratum. Four PFT systems were in use, totalling $4 \times 4=16$ beakers. Nylon mesh $(100 \mu \mathrm{m})$ was placed on top of each beaker to spread the water pulse falling into the beaker and to avoid the possible escape of crawling juveniles.

Two types of water were used: (1) tap water (Jyväskylän Energia/Alva municipal water system) that was kept in large buckets and aerated for at least $48 \mathrm{~h}$ before use and (2) aerated well water (University of Jyväskylä, Ambiotica building). The water quality information for the tap and well water is given in Table 1 . The water temperature was kept at $18^{\circ} \mathrm{C}$.

The 1st rearing experiment: effect of water source and food quantity

Four treatments were established: (1) well water and high food concentration $(0.250 \mu \mathrm{l} / \mathrm{l})$, (2) well water and low food concentration $(0.125 \mu \mathrm{l} / 1)$, (3) tap water and high food concentration $(0.250 \mu \mathrm{l} / \mathrm{l})$ and (4) tap water and low food concentration $(0.125 \mu \mathrm{l} / \mathrm{l})$. In the low and high food treatments, 1 and $2 \mu \mathrm{l}$ of both food types (ShellFish Diet ${ }^{\circledR}$ and Nanno 3600®) in a 1:1 ratio was added to each of the waters, respectively. Twenty randomly selected, newly metamorphosed juveniles were allocated to each beaker, totalling 4 treatments $\times 4$ replicate beakers $\times 20=320$ juveniles. The 1st rearing experiment lasted for 3 weeks, but the data on the juveniles' length were collected at the 2-week time point due to a low number of individuals thereafter for juvenile length analyses (see below).

The 2nd rearing experiment: effect of food quantity

Only well water was used in this experiment. The four food concentrations were $0.125,0.250,0.375$ and $0.500 \mu 1 / 1$ of food (ShellFish $\operatorname{Diet}{ }^{\circledR}$ and Nanno $3600 \AA)$ in a ratio of $1: 1$. The initial number of newly metamorphosed mussel juveniles per beaker was 40 , totalling 4 treatments $\times 4$ replicates $\times 40=640$ juveniles. The experiment lasted for 10 weeks, but the juvenile length data were collected at the 4-week time point due to a low number of individuals thereafter for juvenile length analyses (see below).

Survival and length measurements

Survival and growth monitoring were performed at the 1-week (1st experiment) or 2-week (2nd experiment) time marks. The beakers were emptied, and the juveniles were collected using a $250 \mu \mathrm{m}$ sieve to count living and dead juveniles. Living juveniles moved their foot or kept their valve shut. Dead juveniles had an empty, open shell or had no movement of the foot within 1-2 min of observation. In these monitoring checks, the shell length of a randomly selected subsample was measured using a scaled ocular of the microscope. The number of lost juveniles was estimated, and the sand was replaced. Beaker-specific numbers of juveniles measured for length at the 2-week time point-the data of which were used in the statistical analysis on the effect of water type and food concentration on juvenile survival and size for the 1st experiment (see below)—varied

Table 1 Water quality information for tap and well water

\begin{tabular}{llllll}
\hline Water source & $\mathrm{pH}$ & Iron $(\mu \mathrm{g} / \mathrm{l})$ & Hardness $(\mathrm{mmol} / \mathrm{l})$ & Manganese $(\mu \mathrm{g} / \mathrm{l})$ & Electrical conductivity $(\mathrm{mS} / \mathrm{m})$ \\
\hline Tap water $^{\mathrm{a}}$ & 8.03 & 30 & 0.56 & 0 & 14.05 \\
Well water $^{\mathrm{b}}$ & 6.7 & 38 & 0.01 & $<2$ & 13.1 \\
\hline
\end{tabular}

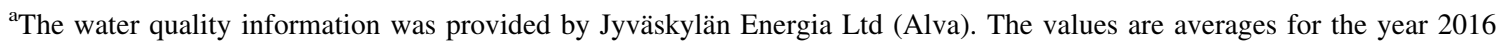

${ }^{\mathrm{b}}$ Analysed by Eurofins Environment Testing Ltd in April 2016 
from 2 to 17. The beaker-specific numbers of juveniles measured for length at the 4-week time point-used in the statistical analysis on the effect of food concentration on juvenile survival in the 2 nd experiment (see below)—varied from 1 to 15 .

\section{Statistical analyses}

Survival rate and average shell length were calculated for each replicate beaker. These beaker-specific values were then used as the response variable in the analyses of variance (ANOVA), with individual beakers as the statistical unit. In the 1 st rearing experiment, the factors included water (tap, well) and food quantity (high, low); in the 2nd rearing experiment, only the food (four levels) was included as a factor. Because of the low survival rate of the juvenile mussels in one of the replicate beakers in the 1st experiment, statistical analyses were performed using data from the 2-week time point in this experiment. Even so, the length data were not available for one replicate beaker in the tap water and low food concentration treatment-in all other treatments, the length data were available for all four replicate beakers $(n=4)$. In the 2 nd experiment, the survival rate was examined at the end of the 10 -week monitoring period. However, since the number of juveniles decreased over time, growth differences were analysed at the 4-week time point in the 2nd experiment. Because of human error, the length data were not available for one replicate beaker in the $0.125 \mu \mathrm{l} / 1$ food concentration and for one replicate beaker in the $0.250 \mu \mathrm{l} / \mathrm{l}$ food concentration treatment of the 2 nd experiment. In all the other treatments, the length data were available for all four replicate beakers $(n=4)$. In addition, to fulfil the criterion of homoscedastic variance, the response variable survival had to be $\log _{10}$-transformed prior to ANOVA. Tukey's test was used to compare potential differences between food quantity groups and survival rate in the 2 nd experiment. A remarkable number of juveniles were lost between monitoring points (see "Results")—-they were not found at all, either dead or alive. Survival rates were calculated by comparing the observed number of living juveniles to the initial number of juveniles allocated to each beaker at the beginning of the experiment.

\section{Results}

1st rearing experiment

After 2 weeks, the mean \pm S.E. survival of the juvenile mussels was 2.7 times higher in well water (49 $\pm 6 \%$, low and high food combined) than in tap water $(18 \pm 6 \%$, low and high food combined) (ANOVA, the effect of food concentration, $F_{1,16}=14.479, \quad P=0.003$, Fig. 2). On average, mean \pm S.E. survival rate was 2.1 times higher in high food concentration ( $46 \pm 6 \%$; well and tap water combined) than in low food concentration $(22 \pm 6 \%$, well and tap water combined) (ANOVA, $F_{1,16}=8.363, P=0.014$, Fig. 2 ). The replicate unit with the highest survival rate, $100 \%$, was in well water/high food concentration-the lowest, $0 \%$, was in tap water/low food treatment. In ANOVA, interaction between the water source and food concentration was not significant on juvenile survival $\left(F_{1,16}=2.317\right.$, $P=0.154)$. After 2 weeks of rearing, the average mean \pm S.E. length of juvenile mussels was greater in well water $(473 \pm 16 \mu \mathrm{m})$ than in tap water $(385 \mu \mathrm{m} \pm 17 \mu \mathrm{m})$ (ANOVA, effect of culture water,

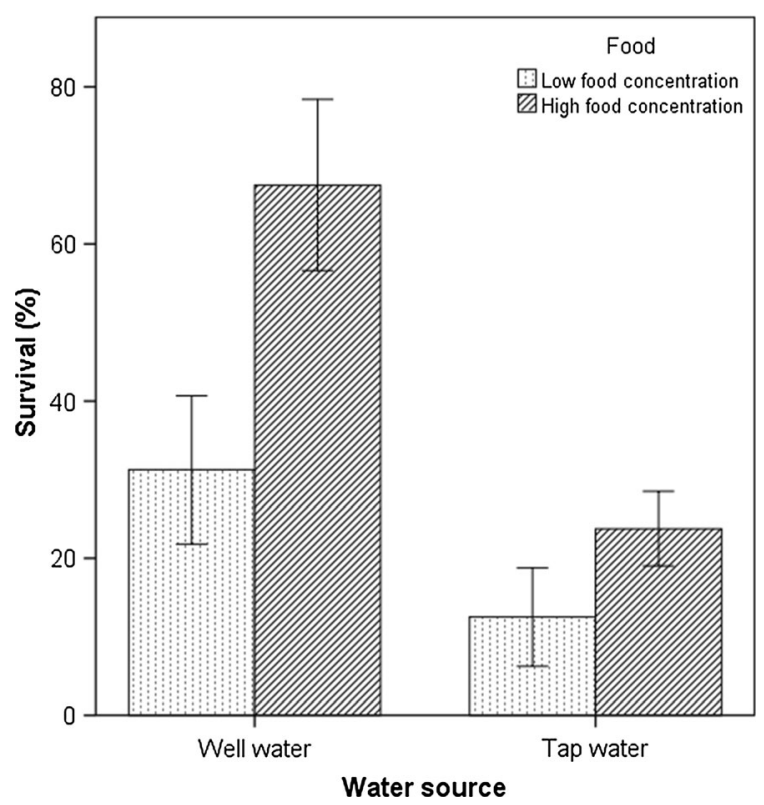

Fig. 2 Mean replicate-specific survival ( \pm S.E. of the mean) of M. margaritifera juveniles in high and low food in tap and well water in the 1 st experiment after 2 weeks of rearing $(n=4$ replicate beakers per treatment in well water and $n=3$ replicate beakers per treatment in tap water) 
$F_{1,15}=15.974, P=0.002$, Fig. 3, low and high food treatments combined). Instead, the effect of food concentration on the length of juveniles was not statistically significant (ANOVA, the effect of food concentration, $F_{1,15}=1.345, P=0.271$, Fig. 3 ). As in the case of survival, the interaction between water source and food concentration was not significant in ANOVA on juvenile length $\left(F_{1,15}=2.566\right.$, $P=0.137)$. Among the juveniles that did not survive, many were not found dead but were instead missing. The number of juveniles that were lost (not found dead or alive) was high; the beaker-specific proportion of juveniles that had gone missing was $0-45 \%$ in well water/high food, $35-80 \%$ in well water/low food, $30-35 \%$ in tap water/high food and $20-65 \%$ in tap water/low food treatment.

The accuracy of the PFT system was assessed by observing the precision of the frequency and volume of water delivery. The delivery occurred in a timely manner. The water pulses were observed to be of equal volume, and adjustments were not needed. Later in the experiments, two nozzles were clogged by debris in the delivery water, causing an obstruction to the water flow.

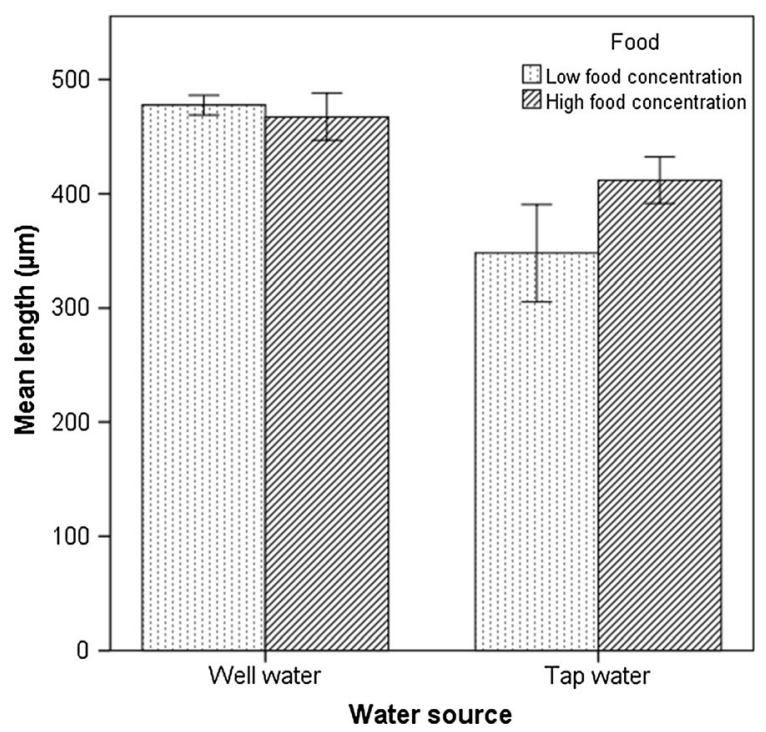

Fig. 3 Mean average replicate-specific length ( \pm standard error of the mean) of $M$. margaritifera juveniles in high and low food concentration in tap and well water in the 1st experiment after 2 weeks of rearing $(n=4$ replicate beakers per treatment in well water and $n=3$ replicate beakers per treatment in tap water) 2nd rearing experiment

There were statistically significant differences between feeding treatments in the mean survival of the juveniles (ANOVA, $F_{3,14}=19.211, P<0.001$ ). The highest mean \pm S.E. 10-week survival, $42 \pm 10 \%$, was observed in the $0.250 \mu \mathrm{l} / \mathrm{l}$ food concentration (Fig. 4). However, it did not differ significantly from the $0.375 \mu \mathrm{l} / \mathrm{l}$ concentration with a mean \pm S.E. survival rate of $21 \pm 19 \%$ (Tukey's test, $P=0.864$, Fig. 4). Another homogenous group was formed by the highest and the lowest food concentration $(0.125$ and $0.500 \mu \mathrm{l} / \mathrm{l})$, which had mean survival rates of around $1 \%$ and did not differ significantly from each other (Tukey's test, $P=1.000$ ). The difference in mean survival between food concentrations 0.125 and $0.250 \mu \mathrm{l} / \mathrm{l}$ was statistically significant (Tukey's test, $P=0.001$ ); this was also true between the food concentrations 0.125 and $0.375 \mu \mathrm{l} / \mathrm{l}$ (Tukey's test, $P=0.003$ ). The differences in the mean survival between concentrations of 0.250 and $0.500 \mu \mathrm{l} / 1$-as well as between 0.375 and $0.500 \mu \mathrm{l} / \mathrm{l}$-were also statistically significant (Tukey's test, $P=0.001$ and $P=0.005$, respectively). The highest survival in a single replicate unit during the 10 -week monitoring period was $58 \%$ in one of the beakers in the $0.250 \mu \mathrm{l} / 1$ food concentration. The same as in the 1 st rearing experiment, the number of lost juveniles (found neither dead nor alive) was high: $23-38 \%$ per beaker

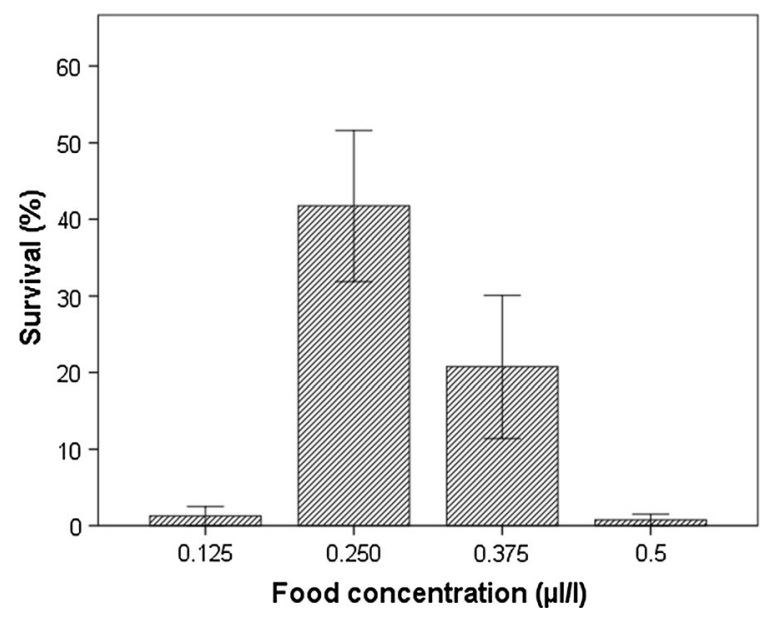

Fig. 4 Mean replicate-specific survival ( \pm standard error of the mean) of $M$. margaritifera juveniles in four food concentration treatments at the end of the 2nd 10-week rearing experiment using well water $(n=4$ replicate beakers per treatment) 
in $0.125 \mu \mathrm{l} / \mathrm{l}, 30-45 \%$ in $0.250 \mu \mathrm{l} / \mathrm{l}, 15-30 \%$ in $0.375 \mu \mathrm{l} / \mathrm{l}$ and $20-25 \%$ in $0.500 \mu \mathrm{l} / \mathrm{l}$ food concentration. At the 4-week time point, the mean average beaker-specific length of the juveniles did not differ between food treatments (ANOVA, $F_{10,13}=1.187$, $P=0.364$, Fig. 5); the mean \pm S.E. length of the juveniles overall for the 14 beakers was $475 \pm 9 \mu \mathrm{m}$.

\section{Discussion}

Kunz et al. (2020) recently described and tested a PFT auto-feeding beaker system for the laboratory culture of juvenile freshwater mussels. However, before the present study, the PFT method in the culture of newborn juvenile $M$. margaritifera-as an alternative to traditional methods- had not been studied. The present results regarding the survival of juveniles are comparable to previous rearing experiments with juvenile mussels. Artificially reared mussels' survival after 2 months has usually been less than $50 \%$, and it is often less than 20\% (Gatenby et al., 1997; Rogers, 1999; Beck \& Neves, 2003; Beaty \& Neves, 2004). The artificial breeding of $M$. margaritifera juveniles that Eybe et al. (2015) attempted using Hruska boxes resulted in survival rates ranging from 7 to $98 \%$ within 110 days. A semi-natural culture of $M$. margaritifera juveniles by Lavictoire et al. (2016) resulted in survival rates ranging from 14 to 55\% within lengthy culture periods of 1-2 years. Between-box variation in

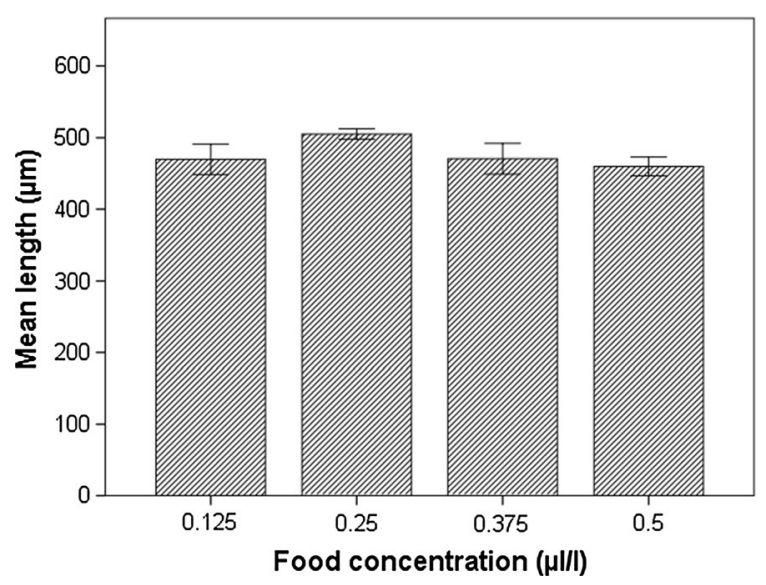

Fig. 5 Mean average replicate-specific growth ( \pm standard error of the mean) of $M$. margaritifera juveniles in four food concentration treatments at the 4-week time point in the 2nd 10 -week rearing experiment using well water $(n=4$ replicate beakers per treatment) the survival of M. margaritifera juveniles in a 55 days culture by Marwaha et al. (2017) was extremely large, from 0 to $100 \%$. However, Scheder et al. (2014) achieved a mean survival of $M$. margaritifera juveniles during a 1 years box culture as high as $96.3 \%$. In the PFT experiment by Kunz et al. (2020), the mean survival of M. falcata juveniles was $23 \%$ at day 357 . The mean survival of $M$. margaritifera juveniles in the present 10-week PFT experiment, 16\%, is not high, but it fits the range of the previous culture results for this species.

Lake or river water is usually used to rear unionids (e.g. Barnhart, 2006; Eybe et al., 2013; Marhawa et al., 2017). However, not all rearing facilities have access to natural water and must use tap or well water as an alternative. In addition, exposure to micro-predators (Rhabdocoela flatworms) (Zimmerman, 2003) and harmful micro-organisms (e.g. opportunistic protozoan parasites, fungal infections) may be lower when using tap/well water vs lake/river water. In the present experiments, the use of tap water resulted in significantly higher mussel mortality than the use of well water. In the 1st rearing experiment, the juveniles reared in well water were also larger in size than the juveniles reared in tap water. The tap water had a higher $\mathrm{pH}$ value and $>50$ times higher hardness than the well water. Tap water is sometimes treated with chemicals such as chlorine, which has been shown to cause mortality in blue mussels, Mytilus edulis (Linnaeus, 1758) (Thompson et al., 1997). Furthermore, the ageing process used for the tap water may not completely remove the chlorine, making it less suitable for $M$. margaritifera juveniles than well water. In the future, PFT culturing of M. margaritifera juveniles should be attempted using lake or river water. In addition, the use of algae and detritus mix as a food source has led to good survival results in traditional Hruska box cultures (e.g. Eybe et al., 2013; Marwaha et al., 2017) and should therefore also be tested with PFT. The use of detritus and lake or river water may expose juveniles to micro-predators present in natural waters. In the present study, no micropredators were observed in either the tap or well water treatments. Thus, the avoidance of micro-predators may be a benefit of well/tap water-based cultures.

In both rearing experiments, the food concentration of the water had a statistically significant effect on the juveniles' survival. The food concentration of $0.250 \mu 1 / 1$ resulted in the highest survival rate. 
Because concentrations higher or lower than $0.250 \mu \mathrm{l} /$ 1 did not result in higher survival, it can be concluded that the juveniles' survival was not limited by the amount of food they received. According to Hruska (1999), abundant food can accelerate the growth of juveniles, but the excess food can also block the substrate and further the growth of algae by providing nutrients, thus decreasing the oxygen available to juveniles. The present results were in accordance with this, indicating that there is an optimal feeding level for juvenile $M$. margaritifera, above which survival rates start to decrease. Although the survival differences between food concentration treatments were clear in the 2nd experiment, the differences in juvenile length (growth) were not statistically significant. This was in accordance with the results of the 1 st experiment, indicating that growth differences may be harder to determine than survival differences. However, it is important to note that length measurements were performed on living juveniles, which may have partly masked the possible growth effects of food treatments if the slowly growing individuals were the first to die.

Even though the PFT system could potentially be used for the mass culture of $M$. margaritifera juveniles, the PFT system, before anything, may be an ideal way to carry out replicated, manipulative experiments on juvenile cultures as well as their tolerances to different water source parameters or contaminants. One benefit of the PFT system is that juveniles are divided into separate units so that potential problems, such as pathogens and predators, do not necessarily contaminate the entire mussel culture. In a PFT culture, juveniles automatically receive a continuous supply of fresh water and food, ensuring constant conditions.

The small size of juveniles and the use of fine sand as a substrate make juvenile handling challenging. Removing juveniles from the sand substrate for monitoring likely caused them physical damage and stress. Detecting juveniles in the sand is also difficult. However, sand offers juveniles a natural substrate that allows them to burrow and potentially prevents them from being carried out of the beaker with the overflow. A considerable number of juveniles were lost during the present experiments. Even though juvenile freshwater mussels are able to crawl up the side of a beaker and sometimes are lost from their containers because of this (Rogers, 1999; Zimmerman, 2003; Barnhart,
2006), it was assumed that the disappearance of juveniles was caused by technical challenges related to weekly/biweekly checks of juvenile survival and length and cleaning of the substrate (i.e. sieving to separate juveniles from sand substrate, flushing juveniles from the sieves to petri dishes and pipetting juveniles when separating dead individuals). It is expected that the longer total handling time due to the longer duration of the 2 nd rearing experiment caused the lower survival in the low food treatment of the 2nd experiment compared to the low food treatment in well water in the 1st experiment. Lavictoire et al. (2016) found that $M$. margaritifera juvenile survival was significantly higher in treatments where the substrate was cleaned less frequently-once a month-than in treatments where the cleaning was done every week. Cleaner substrate may enable mussels to find more and better-quality food, but over-frequent substrate cleaning may expose juveniles to stress, physical damage and may result in a higher level of missing individuals (O'Beirn et al., 1999). In contrast, rearing experiments with unionid juveniles, including removal from the rearing system by sieving and flushing even every 10 days, has yielded high juvenile survival rates (Barnhart, 2006). Nevertheless, the weekly/biweekly monitoring of juveniles' survival and growth in the present study, accompanied by sieving the juveniles from the sand, may have caused stress and decreased the survival and growth rates. PFT culture of $M$. margaritifera juveniles should thus be tested without sand substrate and with less frequent disturbance of the juveniles in terms of sieving, counting and cleaning procedures.

The PFT system appeared to be accurate in terms of the timing and volume of the food solution pulse; however, clogging of the nozzles may decrease the reliability of the system. Therefore, it is important that nozzles and manifolds are cleaned regularly to prevent matter from accumulating in the system.

Kunz et al. (2020) found that the PFT system improved the survival of juvenile mussels (Lampsilis siliquoidea Barnes, 1823; Villosa iris Lea, 1829; Anodonta californiensis Lea, 1852 and M. falcata) compared to other previously tested rearing methods. The results of the present study suggest that the PFT system is suitable for rearing juvenile $M$. margaritifera. In addition, the present study showed that PFT provides an efficient system to study different factors contributing to the survival and growth of juvenile $M$. 
margaritifera. Thus, in accordance with the general conclusions by Kunz et al. (2020), it is believed that PFT offers an ideal system for replicated experimental studies on factors affecting the rearing success of $M$. margaritifera and on water source, feeding and contamination problems. Therefore, the PFT culture system not only offers an alternative rearing system of M. margaritifera juveniles, but it can, in general, contribute to the science-based conservation of this critically endangered species.

Acknowledgements Open access funding provided by University of Jyväskylä (JYU). We are thankful to laboratory technicians Hannu Kautto, Juha Ahonen and Ahti Karusalmi for their help in building and maintaining the pulsed flow-through system and to Tuomo Sjönberg for his help throughout the experiments. We would also like to thank Chris Barnhart (Missouri State University, USA), James Kunz, Eric Brunson and Ning Wang (US Geological Survey, Missouri, USA) for corresponding with us and providing important information regarding the pulsed flow-through system. This research was funded by the Raija and Ossi Tuuliainen Foundation (JT), EU Kolarctic Cross Border Collaboration CBC Programme 2014-2020 (Project SALMUS/KO1017) (JT), the Finnish Foundation for Nature Conservation $(\mathrm{HH})$, the Finnish Cultural Foundation's Central Finland Regional Fund (HH) and the Maj ja Tor Nessling Foundation (MC).

Open Access This article is licensed under a Creative Commons Attribution 4.0 International License, which permits use, sharing, adaptation, distribution and reproduction in any medium or format, as long as you give appropriate credit to the original author(s) and the source, provide a link to the Creative Commons licence, and indicate if changes were made. The images or other third party material in this article are included in the article's Creative Commons licence, unless indicated otherwise in a credit line to the material. If material is not included in the article's Creative Commons licence and your intended use is not permitted by statutory regulation or exceeds the permitted use, you will need to obtain permission directly from the copyright holder. To view a copy of this licence, visit http://creativecommons.org/licenses/by/4.0/.

\section{References}

Allen, D. C. \& C. C. Vaughn, 2009. Burrowing behavior of freshwater mussels in experimentally manipulated communities. Journal of North American Benthological Society 28: 93-100.

Barnhart, C., 2006. Buckets of muckets: a compact system for rearing juvenile freshwater mussels. Aquaculture 254: 233-277.

Barnhart, C., B. Glidewell, A. Maynard, J. Kunz, W. Ning \& L. Ingersoll, 2015. Pulsed flow-through systems for the laboratory culture of early life stages of freshwater mussels.
The Second International Seminar on Rearing of Unionid Mussels, Clervaux, Luxembourg, 24-27 November 2015. Abstract Book, p. 29.

Bauer, G., 1988. Host relationships at reversed generation times: Margaritifera margaritifera L. in Central Europe. Biological Conservation 45: 239-253.

Beaty, B. B. \& R. J. Neves, 2004. Use of natural water flowthrough culture system for rearing juvenile freshwater mussels (Bivalvia: Unionidae) and evaluation of the effects of substrate size, temperature, and stocking density. American Malacological Bulletin 19: 113-120.

Beck, K. \& R. J. Neves, 2003. An evaluation of selective feeding by three age groups of the rainbow mussel (Villosa iris). North American Journal of Aquaculture 65: 203-209.

Bowden, W. B., D. B. Arscott, D. Pappathanasi, J. C. Finlay, J. M. Glime, J. Lacroix, C. L. Liao, A. Hershey, T. Lampella, B. Peterson, W. Wollheim, K. Slavik, B. Shelley, M. B. Chesterton, J. A. Lachance, R. M. Leblanc, M. Steinman, A. M. Suren \& S. B. Group, 1999. Roles of Bryophytes in stream ecosystems. Journal of the North American Benthological Society 18: 151-184.

Buddensiek, V., 1995. The culture of juvenile freshwater pearl mussels Margaritifera margaritifera $L$. in cages: a contribution to conservation programmes and the knowledge of habitat requirements. Biological Conservation 74: 33-44.

Chowdhury, M. M. R., J. K. Salonen, T. J. Marjomäki \& J. Taskinen, 2017. Interaction between the endangered freshwater pearl mussel Margaritifera margaritifera, the duck mussel Anodonta anatina and the fish host (Salmo): acquired and cross immunity. Hydrobiologia 810: 273-281.

Chowdhury, M. M. R., T. J. Marjomäki \& J. Taskinen, 2019. Effect of glochidia infection on growth of fish: freshwater pearl mussel Margaritifera margaritifera and brown trout Salmo trutta. Hydrobiologia. https://doi.org/10.1007/ s10750-019-03994-4.

Eybe, T., F. Thielen, T. Bohn \& B. Sures, 2013. The first millimeter - Rearing juvenile freshwater pearl mussels (Margaritifera margaritifera L.) in plastic boxes. Aquatic Conservation: Marine and Freshwater Ecosystems 23: 964-975.

Eybe, T., F. Thielen, T. Bohn \& B. Sures, 2015. Influence of the excystment time on the breeding success of juvenile freshwater pearl mussels (Margaritifera margaritifera). Aquatic Conservation: Marine and Freshwater Ecosystems 25: $21-30$.

Gatenby, C. M., B. C. Parker \& R. J. Neves, 1997. Influence of sediment and algal food on cultured juvenile freshwater mussels. Journal of North American Benthological Society 15: 587-609.

Geist, J., 2010. Strategies for the conservation of endangered freshwater pearl mussels (Margaritifera margaritifera L.): a synthesis of conservation genetics and ecology. Hydrobiologia 644: 69-88.

Gosselin, M. P., 2015. Conservation of the freshwater pearl mussel (Margaritifera margaritifera) in the river Rede, UK: identification of instream indicators for catchmentscale issues. Limnologica 50: 58-66.

Gum, B., M. Lange \& J. Geist, 2011. A critical reflection on the success of rearing and culturing juvenile freshwater mussels with a focus on the endangered freshwater pearl mussel 
(Margaritifera margaritifera L.). Aquatic Conservation: Marine and Freshwater Ecosystems 21: 743-751.

Hastie, L. C. \& M. R. Young, 2003. Conservation of the freshwater pearl mussel. I: Captive breeding techniques. Conserving Natura 2000 Rivers Conservation Techniques Series No. 2, University of Aberdeen, Culterty Field Station, 26.

Howard, J. \& K. M. Cuffey, 2006. The functional role of native freshwater mussels in the fluvial benthic environment. Freshwater Biology 51: 460-474.

Hruska, J., 1992. The freshwater pearl mussel in South Bohemia: evaluation of the effect of temperature on reproduction, growth and age structure of the population. Archiv für Hydrobiologie 126: 181-191.

Hruska, J., 1999. Nahrungsansprüche der Flußperlmuschel und deren halbnatürliche Aufzucht in der Tschechischen Republik (Dietary requirements and semi-natural rearing of freshwater pearl mussel in the Czech Republic). Heldia 4: 69-79.

Ingersoll, C. G., N. J. Kernaghan, T. S. Gross, C. D. Bishop, N. Wang \& A. Roberts, 2007. Laboratory toxicity testing with freshwater mussels. In Farris, J. L. \& J. H. van Hassel (eds), Freshwater Bivalve Ecotoxicology. SETAC Books, CRC Press, Taylor \& Francis, Boca Raton: 95-149.

IUCN 2019. The IUCN Red List of Threatened Species. Version 2019-3. http://www.iucnredlist.org. Downloaded on 10 December 2019.

Kunz, J. L., E. L. Brunson, M. C. Barnhart, E. A. Glidewell, N. Wang \& G. G. Ingersoll, 2020. Pulsed flow-through autofeeding beaker systems for the laboratory culture of juvenile freshwater mussels. Aquaculture. https://doi.org/10. 1016/j.aquaculture.2020.734959.

Lavictoire, L., E. Moorkens, A. Ramsay \& R. Sweeting, 2016. Effects of substrate size and cleaning regime on growth and survival of captive-bred juvenile freshwater pearl mussels, Margaritifera margaritifera (Linnaeus, 1758). Hydrobiologia 766: 89-102.

Layzer, J. B., M. E. Gordon \& R. M. Anderson, 1993. Mussels: The forgotten fauna of regulated rivers. A case study of the Caney Fork River. Regulated Rivers Research \& Management 8: 63-71.

Lopes-Lima, M., R. Sousa, J. Geist, D. C. Aldridge, R. Araujo, J. Bergengren, Y. Bespalaya, E. Bódis, L. Burlakova, D. Van Damme, K. Douda, E. Froufe, D. Georgiev, C. Gumpinger, A. Karatayev, Ü. Kebapçi, I. Killeen, J. Lajtner, B. M. Larsen, R. Lauceri, A. Legakis, S. Lois, S. Lundberg, E. Moorkens, G. Motte, K.-O. Nagel, P. Ondina, A. Outeiro, M. Paunovic, V. Prié, T. von Proschwitz, N. Riccardi, M. Rudzīte, M. Rudzītis, C. Scheder, M. Seddon, H. Şereflişan, V. Simić, S. Sokolova, K. Stoeckl, J. Taskinen, A. Teixeira, F. Thielen, T. Trichkova, S. Varandas, H. Vicentini, K. Zajac, T. Zajac \& S. Zogaris, 2017. Conservation status of freshwater mussels in Europe: state of the art and future challenges. Biological Reviews 92: 572-607.

Marwaha, J., K. H. Jensen, P. J. Jakobsen \& J. Geist, 2017. Duration of the parasitic phase determines subsequent performance in juvenile freshwater pearl mussels (Margaritifera margaritifera). Ecology and Evolution 7: 1375-1383.
Matisoff, G., F. B. Fisher \& S. Matis, 1985. Effects of benthic macroinvertebrates on the exchange of solutes between sediments and freshwater. Hydrobiologia 122: 19-33.

McCall, P. L., M. J. S. Tevesz \& S. F. Schwelgien, 1979. Sediment mixing by Lampsilis radiata siliquoidea (Mollusca) from western Lake Erie. Journal of Great Lakes Research 5: 105-111.

McCall, P. L., M. J. S. Tevesz, X. S. Wang \& J. R. Jackson, 1995. Particle mixing rates of freshwater bivalves $-A n$ odonta grandis (Unionidae) and Sphaerium striatinum (Posodoodae). Journal of Great Lakes Research 21: 333-339.

Moorkens, E., 2011. Margaritifera margaritifera. The IUCN Red List of Threatened Species 2011.

Moorkens, E. \& I. J. Killeen, 2014. Assessing near-bed velocity in a recruiting population of the endangered freshwater pearl mussel (Margaritifera margaritifera) in Ireland. Aquatic Conservation: Marine and Freshwater Ecosystems 24: 853-862.

Negus, C. L., 1966. A quantitative study of growth and production of unionid mussels in the river Thames at Reading. Journal of Animal Ecology 35: 513-532.

O’Beirn, F. X., R. J. Neves \& M. B. Steg, 1999. Survival and growth of juvenile freshwater mussels (Unionidae) in a recirculating aquaculture system. American Malacological Bulletin 14: 165-171.

Österling, M. E., L. A. Greenberg \& B. L. Arvidsson, 2008. Relationship of biotic and abiotic factors to recruitment patterns in Margaritifera margaritifera. Biological Conservation 141: 1365-1370.

Patterson, M., R. Mair, N. Eckert, C. Gatenby, T. Brady, J. Jones, B. R. Simmons \& J. Devers, 2018. Freshwater Mussel Propagation for Restoration. Cambridge University Press, Cambridge. https://doi.org/10.1017/ 9781108551120.

Rogers, S. O., 1999. Population biology of the tan riffleshell (Epioblasma florentina walkeri) and the effects of substratum and light on juvenile mussel propagation. Master's Thesis, Virginia Polytechnic Institute and State University, Blacksburg, Virginia.

Salonen, J. K. \& J. Taskinen, 2017. Electrofishing as a new method to search for unknown populations of the endangered freshwater pearl mussel Margaritifera margaritifera. Aquatic Conservation: Marine and Freshwater Ecosystems 27: 115-127.

Salonen, J. K., T. J. Marjomäki \& J. Taskinen, 2016. An alien fish threatens an endangered parasitic bivalve: the relationship between brook trout (Salvelinus fontinalis) and freshwater pearl mussel (Margaritifera margaritifera) in northern Europe. Aquatic Conservation: Marine and Freshwater Ecosystems 26: 1130-1144.

Salonen, J. K., P.-L. Luhta, E. Moilanen, P. Oulasvirta, J. Turunen \& J. Taskinen, 2017. Atlantic salmon (Salmo salar) and brown trout (Salmo trutta) differ in their suitability as a host for the endangered freshwater pearl mussel (Margaritifera margaritifera) in northern Fennoscandian rivers. Freshwater Biology 62: 1346-1358.

Scheder, C., B. Lerchegger, M. Jung, D. Csar \& C. Gumpinger, 2014. Practical experience in the rearing of freshwater pearl mussels (Margaritifera margaritifera): advantages of 
a work-saving infection approach, survival, and growth of early life stages. Hydrobiologia 735: 203-212.

Schmidt, C. \& R. Vandré, 2010. Ten years of experience in the rearing of young freshwater pearl mussels (Margaritifera margaritifera). Aquatic Conservation: Marine and Freshwater Ecosystems 20: 735-747.

Strayer, D. L., N. F. Caraco, J. J. Cole, S. Findlay \& M. L. Pace, 1999. Transformation of freshwater ecosystems by bivalves: a case study of zebra mussels in the Hudson River. BioScience 49: 19-27.

Taskinen, J., P. Berg, M. Saarinen-Valta, S. Välilä, E. Mäenpää, K. Myllynen \& J. Pakkala, 2011. Effect of $\mathrm{pH}$, iron and aluminum on survival of early life history stages of the endangered freshwater pearl mussel, Margaritifera margaritifera. Toxicology and Environmental Chemistry 93: 1764-1777.

Thomas, G. R., J. Taylor \& C. Garcia de Leaniz, 2010. Captive breeding of the endangered freshwater pearl mussel, Margaritifera margaritifera. Endangered Species Research 12: 1-9.

Thompson, I. S., R. Seed, C. A. Richardson, L. Hui \& G. Walker, 1997. Effects of low level chlorination on the recruitment, behavior and shell growth of Mytilus edulis Linneaus in power station cooling water. Scientia Maria 61: 77-85.

Vaughn, C. C., 2018. Ecosystem services provided by freshwater mussels. Hydrobiologia 810: 15-27.

Vaughn, C. C. \& C. C. Hakenkamp, 2001. The functional role of burrowing bivalves in freshwater ecosystems. Freshwater Biology 46: 1431-1446.

Vaughn, C. C., K. B. Gido \& D. E. Spooner, 2004. Ecosystem processes performed by unionid mussels in stream mesocosms: species roles and effects of abundance. Hydrobiologia 527: 35-47.

Vaughn, C. C., S. J. Nichols \& D. E. Spooner, 2008. Community and foodweb ecology of freshwater mussels. Journal of the North American Benthological Society 27: 41-55.

Welker, M. \& N. Walz, 1998. Can mussels control the plankton in rivers? A planktological approach applying a Lagrangian sampling strategy. Limnology and Oceanography 43: $753-762$.

Young, M. R., 1991. Conserving the freshwater pearl mussel (Margaritifera margaritifera L.) in the British Isles and Continental Europe. Aquatic Conservation: Marine and Freshwater Ecosystems 1: 73-77.

Young, M. R., P. J. Cosgrove \& L. C. Hastie, 2001. The Extent of, and Causes for, the Decline of a Highly Threatened Naiad: Margaritifera margaritifera. Ecology and Evolution of Freshwater Mussels Unionoida. Springer, Heidelberg.

Zimmerman, L. L., 2003. Propagation of juvenile freshwater mussels (Bivalvia: Unionidae) and assessment of habitat suitability for restoration of mussels in the Clinch River, Virginia. Master's Thesis, Virginia Polytechnic Institute and State University, Blacksburg, Virginia.

Zimmerman, G. F. \& F. A. de Szalay, 2007. Influence of unionid mussels (Mollusca: Unionidae) on sediment stability: an artificial stream study. Fundamental and Applied Limnology 168: 229-306.

Publisher's Note Springer Nature remains neutral with regard to jurisdictional claims in published maps and institutional affiliations. 